\title{
Nota da Editora
}

Em 2018, a Rebep fez outra importante adequação às práticas editoriais mais atualizadas, tornando sua publicação contínua. Com isso, assim que aceitos e editados, os artigos são imediatamente disponibilizados tanto em nossa página quanto na da SciELO, sendo endereçados para números específicos da Revista que vão sendo compostos ao longo do ano. Dentro dessa lógica, há dois momentos da publicação: um em que os trabalhos são disponibilizados individualmente on-line, cada um em seu tempo; e outro, ao final de cada ano, quando completamos os três números que compõem o volume anual. Isso dá à Rebep, duas vantagens. A primeira é a maior celeridade com que autores e leitores têm acesso aos artigos, evitando o risco de que a produção fique ultrapassada antes mesmo de ser publicada. A segunda é que, a despeito da divulgação individualizada de cada artigo, a Revista pode organizar a produção do ano em torno de temas que conferem identidade a cada um dos números.

Desse modo, a concepção dos três números de 2018 organizou a produção científica da Rebep a partir dos três eixos essenciais da demografia e dos estudos populacionais: fecundidade, mortalidade e movimentos migratórios. 0 primeiro número reúne trabalhos que discutem aplicações de técnicas de estimação direta e indireta da fecundidade e como as relações familiares afetam não apenas as escolhas reprodutivas, mas também outras decisões atinentes ao bem-estar de seus membros, incluindo as opções educacionais e ocupacionais. 0 segundo número foca no envelhecimento populacional, na saúde dos indivíduos e em evidências históricas e atuais sobre a mortalidade. 0 terceiro número, por fim, centrado na dinâmica espacial da população, engloba trabalhos sobre migração internacional, territorialização e ocupação de migrantes e inter-relações com o mercado de trabalho. Estes três números equilibram os elementos formais da análise demográfica e da discussão das técnicas de estimação disponíveis, com o seu uso para aplicações extremamente relevantes que nos ajudam a compreender melhor a dinâmica populacional e sua conexão com os fenômenos socioeconômicos. Tal combinação é, sem dúvida, o que atribui peculiaridade a este periódico, que é o único no Brasil especializado em demografia e estudos populacionais. A Revista, portanto, tende a ser o veículo de primeira escolha das publicações nacionais centradas na análise demográfica, sem, contudo, deixar de acolher e valorizar as contribuições de todas as disciplinas pertinentes ao entendimento das questões populacionais. 
Este primeiro número do volume de 2018 traz trabalhos sobre fecundidade, relações familiares, escolhas e decisões que dependem, em grande medida, dos contextos familiares. 0 artigo de Sacco e Borges investiga se os níveis de fecundidade vêm convergindo, conforme a hipótese amplamente aceita e frequentemente adotada nos estudos prospectivos. Os autores analisam os casos de dois países latino-americanos - Brasil e Argentina -, descrevendo, por meio do uso de técnicas de estimação indireta, as tendências recentes segundo regiões geográficas, nível educacional e condição ocupacional, tomados como indicativos de diferenciação social. Utilizando dados censitários harmonizados entre 1970 e 2010, eles confirmam a ocorrência do processo de convergência, mas este está longe de ser linear e equivalente na comparação entre os dois países. Enquanto no Brasil a convergência é igualmente verificável nas três dimensões sociais adotadas (regional, educacional e ocupacional), na Argentina apenas as diferenças regionais mostram redução inequívoca em todos os períodos analisados.

0 estudo de Coutinho e Golgher também investiga o declínio da fecundidade, com foco no caso brasileiro, que transitou muito rapidamente de taxas elevadas para um nível não apenas abaixo da reposição, mas também inferior àquele declarado como desejado pelas famílias. Adaptando um modelo formulado por Bongarts (2001), os autores decompõem as taxas brasileiras relativas a 1986, 1996 e 2006 em tamanho desejado da família, fecundidade indesejada, preferência por sexo, reposição da mortalidade infantil, efeito tempo observado por meio da variação na idade à maternidade, infertilidade involuntária e preferências competitivas, estas últimas entendidas como outros planos que concorreriam com a maternidade, como o investimento em capital humano e a inserção ocupacional. Como resultado, verifica-se que, no período analisando, houve uma importante mudança qualitativa: as mulheres brasileiras costumavam ter mais filhos do que o desejado e, mais recentemente, passaram a ter menos do que o desejado, embora ainda se observem gravidezes indesejadas em alguns grupos. Outra mudança marcante é que as mulheres mais escolarizadas eram as que desejavam o menor número de filhos, enquanto no período recente são as com menor escolaridade as que desejam menos. Segundo os autores, as chamadas preferências competitivas, responsáveis pela maior parte da redução da fecundidade, parecem estar afetando particularmente as mulheres com menos oportunidades ocupacionais.

Ainda na perspectiva das preferências reprodutivas, o artigo de Carvalho, Wong e Miranda-Ribeiro lança mão das pesquisas qualitativas em profundidade para verificar até que ponto, na cidade brasileira de Belo Horizonte, o número de filhos inferior ao considerado ideal, que predomina entre os casais de alta escolaridade, é resultado de uma escolha ou se representa a incapacidade de implementação de preferências e consequente insatisfação com o resultado alcançado. Dos casais entrevistados, as autoras depreendem haver satisfação com o nível de fecundidade, a despeito da elevada prevalência de discrepância negativa entre número de filhos tidos e o número declarado como ideal. Isso ocorre porque o indicador tradicional de número ideal de filhos é fortemente 
influenciado por normas subjetivas, em grande medida baseadas na experiência pregressa dos pais; e essa concepção idealizada não se sustenta em face das dificuldades reais das circunstâncias efetivamente vivenciadas. Tal discussão é importante porque problematiza um indicador muito tradicional das pesquisas tipo DHS, que procura medir o hiato entre o número de filhos tidos e desejados, mas cujas interpretações precisam ser formuladas com grande cautela.

O quarto artigo deste número, de Carvalho, Gonçalvez e Silva, enfoca também a queda da fecundidade experimentada no Brasil nas ultimas décadas, mas discute uma questão essencialmente metodológica, que é a possibilidade de aplicação da técnica indireta de estimativa de fecundidade de Brass - conhecida como P/F de Brass - em um contexto de rápida queda da fecundidade das adolescentes, como a que ocorreu no país entre 2000 e 2010. 0 declínio mais acentuado na fecundidade do primeiro grupo etário em idade reprodutiva (15-19 anos) resulta em um erro por falta na fecundidade corrente acumulada até o grupo etário de 20 a 24 anos (F2), levando a uma sobre-estimativa da razão P2/F2, geralmente utilizada para ajustar o nível da fecundidade declarada. Ao discutir esse problema e apresentar uma alternativa para corrigir as estimativas relativas ao censo de 2010, o estudo revisa detalhadamente toda a lógica subjacente ao método concebido por Brass e, com isso, oferece uma profunda compreensão de como o método se sustenta, das circunstâncias que podem gerar vieses nas estimativas e das possibilidades de corrigi-las, nos casos em que as estimativas diretas são ainda deficientes e o uso das técnicas indiretas é ainda de grande utilidade.

Os demais artigos que compõem este número discutem as decisões e escolhas que ocorrem nos grupos familiares e dependem de suas circunstâncias. Os estudos de Martins e Machado e de Rizzotto, França e Frio focam nas escolhas educacionais. 0 primeiro examina quais são os fatores que condicionam a escolha do tipo de curso superior no Brasil. Combinando características individuais e familiares, as características dos cursos e os incentivos econômicos das carreiras associadas aos cursos, os autores concluem que os indivíduos de renda domiciliar per capita mais elevada têm suas escolhas positivamente influenciadas pelo retorno esperado dos cursos, tanto no início quanto no decorrer das carreiras. Por outro lado, as escolhas das pessoas dos quartis mais baixos de renda familiar parecem sofrer grande efeito negativo do nível de concorrência pela vaga. Do ponto de vista metodológico, o trabalho faz um interessante uso dos dados ao combinar informações provenientes de censos (e outras fontes sobre ensino superior) de 2000 e 2010 , associando as características individuais e familiares após o final do curso superior (2010) e os atributos dos cursos (concorrência, duração e incentivos econômicos) no momento da tomada de decisão, dez anos antes.

O outro artigo sobre escolha educacional procura identificar como as características dos arranjos familiares afetam a escolha parental por matricular os filhos na rede de pública ou privada de ensino. Usando dados da PNAD de 2015 e um modelo de escolha binária (logit) para a matrícula na rede pública ou privada, é testado um modelo para 
cada tipo de arranjo familiar (casal com filhos, monoparental feminino e monoparental masculino), incluindo um conjunto de variáveis de características da criança, da família e do domicílio. Os resultados mais importantes apontam que as meninas têm maiores chances do que os meninos de estudar numa escola privada se estiverem em um arranjo monoparental feminino. Além disso, para todos os arranjos, os filhos mais velhos possuem maiores chances de frequentar uma escola privada, comparativamente aos mais novos. Quanto aos níveis de ensino, é na educação infantil que há a maior chance de investimento privado das famílias, o que certamente ocorre devido à deficiência da oferta de vagas públicas para este nível, combinada com as necessidades ocupacionais, sobretudo das mães.

0 artigo de Barbosa discute a alocação de tempo de homens e mulheres entre trabalho remunerado, afazeres domésticos e lazer, sendo este último definido de forma residual, ou seja, como o tempo não despendido com trabalho remunerado e trabalho doméstico. Esse tipo de estudo tem despertado grande interesse para as análises demográficas, devido às implicações destas tendências nas escolhas reprodutivas e de formação e dissolução das uniões conjugais. Nunca é demais lembrar que o Brasil é dos poucos países latino-americanos que ainda não possuem uma pesquisa nacional de uso do tempo, mas o fato de a PNAD ter incluído um quesito específico sobre o número de horas dedicadas ao trabalho doméstico desde o início da década de 2000 significou a possibilidade de estudarmos, ainda que muito superficialmente, as características e os efeitos da divisão do trabalho doméstico. Neste artigo, que documenta as tendências observadas no Brasil desde 2001 até 2015 , constata-se que os homens desfrutam de mais horas de lazer do que as mulheres, embora a diferença entre os sexos esteja se reduzindo, já que vêm aumentando mais para as mulheres do que para os homens. As razões para essa elevação são também inteiramente distintas: para os homens, o aumento das horas de lazer decorre da redução nas horas de trabalho remunerado e de um leve crescimento nas horas de trabalho doméstico, enquanto as mulheres diminuíram as horas de trabalho doméstico e mantiveram as horas de trabalho remunerado.

O artigo de Reynolds investiga a relação entre composição familiar e o sexo das crianças no Brasil. Embora não haja, no país, uma cultura de preferência pelo sexo dos filhos, as discrepâncias de rendimentos entre homens e mulheres podem acentuar os diferenciais de gênero desde a infância, no caso de o sexo do filho influenciar a composição domiciliar. Dois tipos de composição são investigados pela autora: a ausência do pai e a presença de uma avó. No primeiro caso, não houve diferença significativa do sexo do primeiro filho no status de união da mãe para a população total, mas restringindo a amostra às mulheres mais vulneráveis, encontrou-se um pequeno aumento na probabilidade de as mulheres estarem em uma união quando o primeiro filho é um menino. Em ambas as amostras observou-se que as mães de duas meninas têm menos probabilidade de se encontrar em uma união comparativamente a uma mãe de dois meninos. Apropriadamente, a autora afirma que não é possível determinar se esses achados devem-se a um viés de gênero, a 
um maior custo de investimento na criação de meninas ou às vantagens comparativas de homens criarem meninos, mas, qualquer que seja a explicação, as meninas podem ficar em desvantagem em relação aos meninos, ao menos do ponto de vista econômico, por não terem os pais vivendo no mesmo domicílio. A autora testa também se o sexo da criança modifica a chance de a mãe estar vivendo com sua própria mãe, ou seja, a avó da criança, o que poderia atenuar os efeitos negativos da ausência do pai. Entre as mulheres mais vulneráveis, que não completaram o ensino médio e tornaram-se mães na adolescência, há um significativo aumento da probabilidade de presença da avó materna quando as duas primeiras filhas são meninas.

A Nota de Pesquisa de Santos e Gonçalves explora uma questão metodológica essencial para o uso das informações censitárias que é a estimativa do grau de subenumeração do grupo etário de 0 a 4 anos, que tende a ser subestimado em relação à população adulta. Chamando a atenção para a importância da correção adequada do tamanho deste grupo para as projeções populacionais e a construção de estatísticas populacionais confiáveis, a nota aborda cinco técnicas distintas para a enumeração da população infantil de 0 a 4 anos, comparando suas potencialidades.

Encerrando este número da Rebep, na seção Ponto de Vista, Jannuzzi é extremamente oportuno por defender a importância crucial das informações estatísticas e dos indicadores sociais para a gestão das políticas públicas no país. Ele traça um detalhado histórico da produção regular e continuada das principais pesquisas do IBGE e conclui demonstrando grande preocupação com os "rumores" de que o Censo de 2020 teria que ser significativamente reduzido, de modo a se adequar às restrições orçamentárias do presente contexto nacional. Infelizmente, desde a publicação deste texto, as expectativas negativas a respeito do Censo Demográfico de 2020 só se agravaram, especialmente com uma declaração recente do ministro da Economia dizendo que o censo deveria restringir-se a um conjunto de dez quesitos. Especialistas em estatísticas, demógrafos e usuários dos censos têm se manifestado publicamente para explicar à opinião pública porque uma mudança nesse sentido seria desastrosa.

Neste início de 2019, despeço-me do cargo de editora da Rebep com a entrega do volume completo de 2018 e com a certeza de que, se temos feito bastante para adequarmos a Revista às melhores práticas editoriais, o caminho é ainda longo e exige muita dedicação para torná-la cada vez mais relevante e dinâmica. A nova editora da Rebep, Paula Miranda-Ribeiro, é talhada para o cargo, pois reúne comprometimento institucional genuíno, discernimento acadêmico e excelente trânsito entre os pares. Ela sabe que o trabalho com a Revista é difícil, sobretudo porque deve ser conciliado com todas as nossas outras atividades acadêmicas, de ensino, pesquisa e gestão. Mas já disse a ela (e repito aqui) que, apesar disso, essa é uma das experiências mais gratificantes da vida acadêmica, porque desenvolve nossas habilidades de interação com os pares, de decisão e de bom senso, atualizando-nos com o que vem sendo produzido e tornando-nos, com isso, melhores demógrafas. 
Quero finalmente registrar meus agradecimentos a todos aqueles que tanto contribuíram para o trabalho destes dois anos. Aos membros do conselho editorial que sempre estiveram a postos para colaborar com ideias e ajudar nas decisões mais difíceis (que são muitas). Dentre os membros do conselho, destaco o papel do coeditor, Gilvan Guedes, que esteve do meu lado nas tarefas editoriais diárias, facilitando nossos desafios com sua enorme capacidade de trabalho e conhecimento abrangente. Agradeço à nossa excelente equipe editorial, encabeçada pela Ana Paula Pyló, que dispensa apresentações, mas a quem não dispensamos sempre os melhores elogios. Com seu bom humor e competência conhecida, manteve a afinação de um time de mulheres supertalentosas que vêm cuidando de toda a produção editorial da Rebep. São elas, Vania Regina Fontanesi (preparação de originais e revisão de português), Patricia Antuña (revisão de inglês), Nairi Aharonián (revisão de espanhol), Fabiana Grassano e Flávia Fábio, da Traço Publicação e Design (projeto gráfico e diagramação) e Ana Claudia Ribeiro da Editora E-papers (conversão em XML). A elas quero expressar todo o reconhecimento pelo trabalho contínuo e diligente. Agradeço enfaticamente também aos pareceristas que disponibilizam seu tempo para emprestar sua expertise ao processo de decisão editorial. E, finalmente, na qualidade de editora, mas ainda mais como demógrafa e cientista social aplicada, agradeço à diretoria da Abep por, acertadamente, fazer da Rebep uma prioridade. 